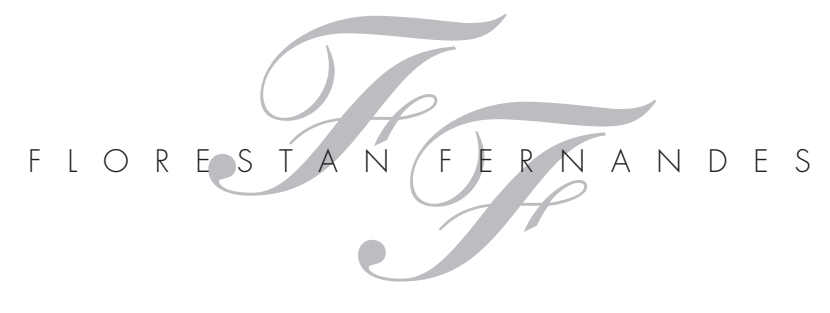

\title{
VIDA E HISTÓRIA NA SOCIOLOGIA DE FLORESTAN FERNANDES
}

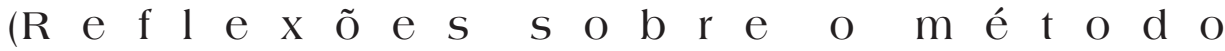

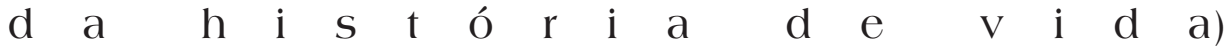

JOSÉ DE SOUZA MARTINS

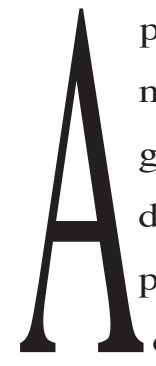

pesar da influência do funcionalismo de origem durkheimiana em alguns dos mais importantes trabalhos de Florestan Fernandes, tinha ele especial preocupação teórica e histórica com a biografia. Não só porque a história pessoal reconstruída na perspectiva do método da história de vida constitui rico documento sociológico, mas também porque em seu entender o homem, inclusive o homem comum, tem de algum modo a possibilidade de intervir ativamente nos processos sociais que protagoniza.

Um de seus últimos trabalhos, cuja introdução está datada de poucos dias antes de sua morte, é justamente uma coletânea de biografias de amigos e heróis (1). Mesmo sendo textos de apreço e homenagem, estão eles bem marcados pela preocupação sociológica de explicar as biografias, descobrir as determinações históricas e sociais que as teceram e que definiram rumos e perfis.

Apesar das preocupações com as determinações que fazem com que a história de cada um não seja mero produto do acaso, a concepção que o professor Florestan tem das histórias pessoais nãoé uma concepção determinista. Por isso mesmo, ao dirigir sua curiosidade científica (e afetiva) para a biografia de determinadas pessoas, o que ele busca é descobrir, sem dúvida, de um lado as alternativas biográficas que a sociedade abre para seus 


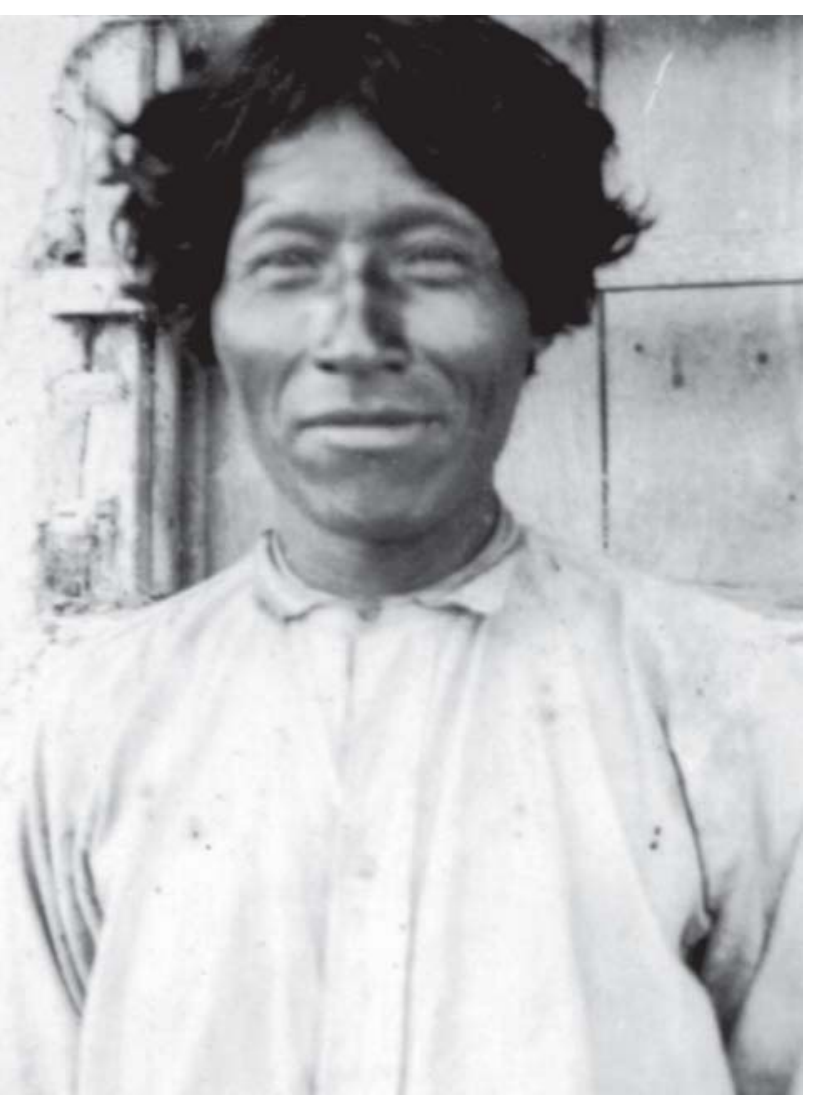

Abaixo, em foto de

Alonso Bispo durante

a conferência

"Psicanálise e

Sociologia", Florestan

está ao microfone e,

à sua esquerda, Mário

Pedrosa; ao lado,

o Tiago Marques

Aipobureu do ensaio

famoso que tem como

subtítulo "Um Bororo

Marginal" - a foto

é de Herbert Baldus

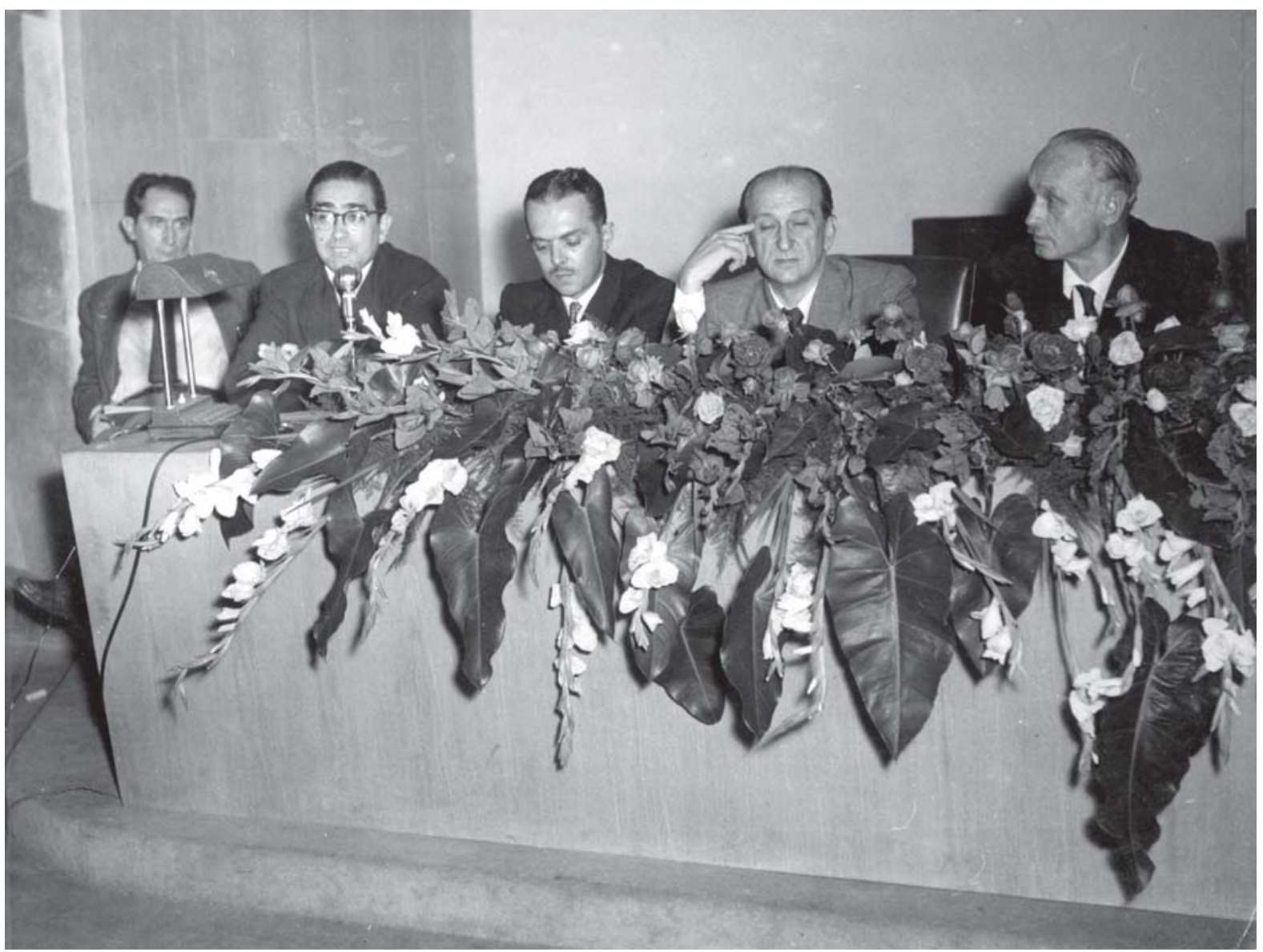


membros (e também as alternativas que fecha). Mas, de outro lado, há em suas obras um significativo interesse pelas biografias que "contrariam" a História, como é o caso da sua própria. Em parte, parece-me, sua concepção da relevância metodológica da biografia está justamente nesse desencontro, na riqueza explicativa que há na história de vida dos que se insurgem contra o destino traçado para sua classe social, como Caio Prado Júnior, a quem devota merecidas palavras de admiração.

Desde o começo de sua carreira, o professor Florestan interessou-se pela biografia como instrumento de conhecimento sociológico. Ainda aluno do curso de Ciências Sociais da Faculdade de Filosofia, Ciências e Letras da Universidade de São Paulo, em 1942, fez uma bem cuidada pesquisa sobre João de Camargo, um líder carismático de Sorocaba (SP), ex-escravo, já falecido, que dera origem a um culto sincrético na região (2). Já nesse tex to pioneiro, ficam claros os marcos de referência que permitem selecionar biografias ricas de contradições e, portanto, ricas de informação sobre as transformações sociais e os embates de cada um com os processos que dão sentido às histórias pessoais. Ele observa que "a personalidade de João de Camargo reflete o meio social em que viveu e foi educado" (3). Era uma premissa corrente no estudo de personalidades e de biografias por parte de antropólogos e sociólogos, sobretudo porque lhes interessava conhecer a relação entre personalidade e cultura e entre personalidade e sociedade. Os estudos de Kardiner e Linton, sobre personalidade básica e personalidade-status, respectivamente, eram nesse tempo referência obrigatória para esses cientistas sociais.

Mas o professor Florestan, em seguida, assinala aquilo que no contraponto define a importância da biografia como documento: "Do ponto de vista teórico, porém, esta proposição do problema tem pouco alcance. [...] conexões dessa espécie podem ser encontradas na vida de outros indivíduos de cor preta, radicados em Sorocaba; elas são normais, no sentido de resultarem de condições de existência social em uma sociedade estratificada e de passado escravocrata". E, então, vai ao ponto que metodologicamente define a rele- vância da biografia na pesquisa sociológica: "O problema específico diz respeito à sensibilidade às solicitações do meio social, revelada por João de Camargo. É nisto que ele se distingue profundamente [...]".

São as histórias singulares, "não-normais", que, ao documentarem desencontros entre personalidade e sociedade, documentam o que efetivamente está acontecendo com esta última. É claro que em seus diferentes estudos biográficos estão postas duas atitudes distintas em relação às biografias. De um lado, é uma a atitude quando se trata de explicar a história concreta de uma pessoa; quando compreender a formação da pessoa e explicar sua trajetória estão no centro de interesse do pesquisador. É o caso de seus estudos sobre Tiago Marques Aipobureu (um estudo de marginalidade social que se tornou célebre), João de Camargo, Luiz Inácio Lula da Silva. Neles, Florestan Fernandes investiga como se dá sociológica e historicamente a produção da biografia, a construção da trajetória pessoal do biografado.

Uma segunda atitude, que é a que estou enfatizando neste texto, é a de encarar a biografia como uma espécie de sucedâneo da experimentação científica. Uma vez que os cientistas sociais, a rigor, não podem fazer experimentos, ao menos por razões éticas, o recurso do confronto entre personalidade e sociedade, entre biografia e História, oferece uma alternativa quase experimental para a verificação de como surgem e se desenrolam os processos sociais. Esses casos têm maior e mais rica densidade de evidências e de informações sobretudo para os estudos sociológicos sobre mudança social.

Apesar de sua sensibilidade em relação à importância sociológica das biografias divergentes, num estudo justamente clássico sobre o método da história de vida, o professor Florestan tem um cuidado teórico refinado na definição das possibilidades de seu uso pelos sociólogos. Sobretudo, reconhece antes de mais nada, discordando, as objeções de cientistas sociais a seu uso: "As críticas sobre as inconveniências da utilização dos chamados documentos pessoais pela Sociologia revelam-se inconsistentes, e, em regra, constituem produtos intelectuais de prenoções 


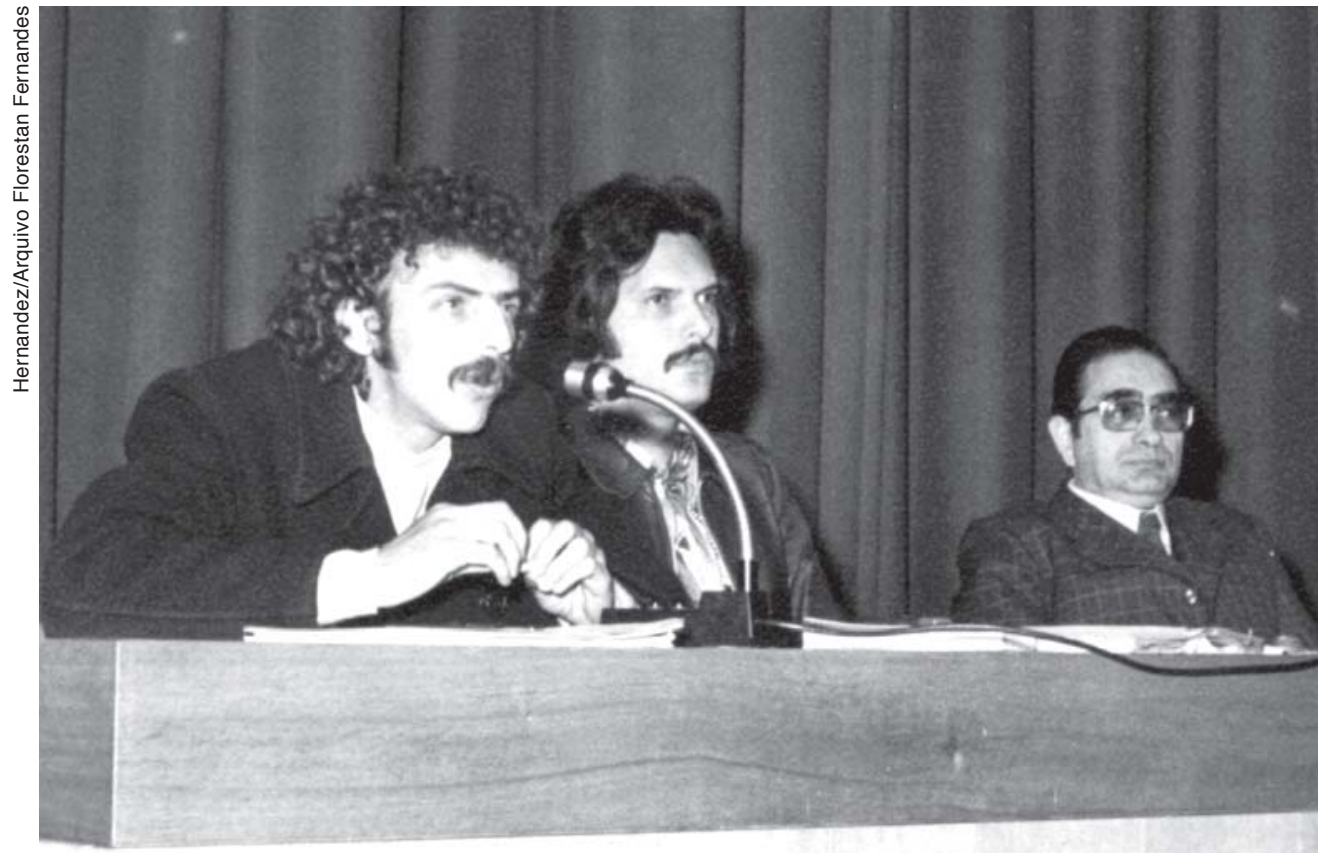

metodológicas, herdadas especialmente do Positivismo" (4).

Nesse trabalho, preocupa-o a objetividade da investigação que lida com a subjetividade dos informantes. Em grande parte, porque há sempre possibilidade de que o sujeito não revele e não saiba revelar o que é e pensa e, portanto, não se constitua em boa fonte de informações sobre o seu ajustamento dinâmico às condições de existência. Além disso, nem todas as biografias são relevantes e reveladoras. Um dos problemas do sociólogo é, justamente, selecionar os casos para a elaboração das histórias de vida. Em outras palavras, entre a biografia e a história de vida há a mediação do trabalho sociológico, para chegar aos tipos, àquilo que é propriamente social e que não se confunde com as peculiaridades do sujeito nem aí se dilui (5). Trata-se não só de encontrar sujeitos de maior significação para definição do típico, mas também de encontrar o que é mais significativo nas biografias. Trata-se, pois, de conseguir "uma base razoável de segurança na seleção dos casos individuais, que podem ser considerados significativos e relevantes para fins definidos de análise" (6). Ao mesmo tempo, ele aponta as incertezas e limitações da observação participante, a técnica de tornar-se parte da sociedade observada, um recurso ainda hoje comum na pesquisa sociológica para assegurar ao sociólogo as dimensões mais ocultas ou de difícil acesso nas relações sociais. E chama a atenção para a importância do procedimento oposto na investigação, a de reconhecer-se e utilizar-se investigativamente como não-parte da sociedade observada, como estranho: "Há muitas posições que um estranho podeocuparemqualquercomunidade" (7) Poucos e competentes sociólogos se interessaram pela importância estratégica da condição de estranho na pesquisa empírica. O estranho e a análise sociológica do estranhamento é um recurso fecundo no estudo de sociedades com as quais não estamos familiarizados, como sugeriu Schutz (8); e no mesmo sentido o autoestranhamento, que se tornou o centro da etnometodologia de Garfinkel (9).

É evidente que a utilização de biografias como documentos em seus trabalhos não o leva a supor que as histórias pessoais interessem ao sociólogo unicamente como pretexto, como meio, para chegar aos processos sociais, especialmente os de mudança social. E que, portanto, as próprias pessoas sejam
Florestan éo

terceiro à direita nesta mesa do $X$ Congresso Latinoamericano de Sociologia realizado em Santiago,

Chile, 1972

4 Cf. Florestan Fernandes, "A História de Vida na Investigação Sociológica: a Seleção dos Sujeitos suas Implicações", in Ensuas Implicaçes", in Ensaios de Sociologia Geral e Aplicada, Sa Paulo, Pioneira, 1960, p. 251

5 Num outro livro, hoje um clássico da sociologia brasileira, Florestan Fernandes define esse estado intermediário entre o dado termediario entre o dado buto e imediato e o mateial da análise sociológica propriamente dita como instâncias empíricas relevantes. É com elas que trabalha o sociólogo. Cf. Florestan Fernandes, Fundamentos Empíricos da Explicação Sociológica, São Paulo, Nacional, 1959, passim.

6 Idem, ibidem, pp. 255-6.

7 Idem, ibidem, p. 258

8 Cf. Alfred Schutz, "E Forastero. Ensayo de Psicología Social" e "La Vuelta al Hogar", in Estudios sobre Teoría So cial, Buenos Aires, cial, Buenos Aires, pp. 107-19.

9 Cf. Harold Garfinkel, Studies in Ethnomethodology, Englewood Cliffs, Prentice Hall, 1967. 
10 Tiago Marques Aipobureu foi um índio bororo, do Mato Grosso, retirado do meio tribal e educado pelos missionários salesianos. Aprendeulínguase e professor, tendo viajad largamente pela Europa para fazer conferências. Tiago Marques recebeu uma dupla e contraditória socialização, que se refletiu dramaticamente em sua vida, até sua morte: ele tornou um homem culturalmente marginal, vivendo no limite de duas culturas radicalmente distintas, a branca e a indígena. Pelos próprios missionários, que como educaram como branco, branco, como índio. Pelo próprios índios, ele era tratado como branco. Em conseqüência, desenvolveu um comportamento de integração insatisfatória em cas orestan Fernandes, "Tiago Marques Aipobureu: um Bororo Marginal", in Mudanças Sociais no Brasil, op. cit., pp. 311-43. Herbert Baldus, que foi professor de Floresta fessor de florestan studo sobre Tiago Marques, também escreveu sobre o assunto. Cf. Herbert Baldus, "O Professor Tiago Marques e o Caçado Aipobureu - a Reação Aipobureu a Reaça de luência de nossa Civilização", in Ensaios de Etnologia Brasileira, $2^{\mathrm{a}}$ edição, São Paulo, Nacional 1979, pp. 92-107.

11 Cf. Florestan Fernandes, $A$ Contestação Necessária, op. cit., p. 80.

12 Idem, ibidem, p. 81

13 Idem, ibidem, p. 82 irrelevantes. A importância histórica de cada um está bem posta nas páginas de apreço do livro recente. E mesmo nos estudos de casos mais antigos e mais claramente acadêmicos o leitor pode constatar que o rigor e a objetividade da investigação não chegam a arruinar a humana identificação com aqueles que estão fragilizados pelos desencontros entre sua história pessoal e os limites das alternativas e possibilidades que a sociedade lhes abre. Em grande parte, essa espécie de identificação afetiva com os que sofrem o drama desse desencontro, como Tiago Marques Aipobureu (10), estáalicerçada num valor que preside o trabalho de todo cientista social: o primado de um destino de liberdade e justiça, de igualdade e alegria, para o gênero humano. Isso já está posto pelos clássicos das ciências sociais: todos eles estão preocupados com a perda de rumos de diferentes grupos sociais em relação a uma trajetória que deveria leválos seja à ordem (e ao progresso), seja à racionalidade, seja à utopia da igualdade e da não-exploração. Por isso mesmo, as idéias fundamentais desses autores estão centradas em problemas que reclamam a pesquisa e a explicação do sociólogo: a anomia, a irracionalidade, a alienação.

Uma concepção diretamente ligada a essas preocupações na valorização sociológica da história de vida é a de que são sociologicamente relevantes as biografias liminares, as de pessoas que se encontram no limite de situações históricas e/ou étnicas, como João de Camargo ou Tiago Marques Aipobureu. Um sociólogo de formação positivista provavelmente veria nessas situações os momentos de crise da ordem social, enquantoque um marxismolimitadopela ortodoxia aí enxergaria a mudança social ou o limiar e o anúncio da revolução.

Sem desconsiderar essas possibilidades propostas por perspectivas antagônicas, Florestan Fernandes examina outras rupturas. Com freqüência esse exame está marcado pela preocupação em saber o que as pessoas fazem consigo mesmas nesses momentos de consciência dividida. São eles momentos em que o rumo pré-traçado pela origem e pela situação de classe entra em crise. São momentos em que o destino e a consciência se confrontam. São momentos não só dramáti- cos, mas ricos de evidências sobre os processos sociais, as possibilidades históricas abertas pelo esgotamento dos mecanismos de recriação da ordem. Não só as rupturas propriamente sociais são relevantes para o estudo sociológico das transformações sociais. Mas também as rupturas interiores, "a ressocialização da pessoa dentro de mores antagônicos" (11).

É nesse momento que se encontra explicação para o que ele chama de "ruptura moral plena” (12). E é aí também que está o núcleo de sua preocupação com o atraso das consciências em relação às possibilidades de mudança social que são abertas pelo processo histórico. Para compreendermos esse aspecto central de sua sociologia é necessário levar em conta que Florestan Fernandes, apesar de militante e confessadamente revolucionário, tem uma concepção dinâmica e propriamente sociológica das classes sociais. Na verdade, acima de classes e categorias sociais, há para ele, como para os clássicos da sociologia, o ser humano, o destinatário por excelência das condutas sociais e do agir histórico. Por isso, desde os trabalhos mais antigos até os mais recentes, o que o preocupa nas classes sociais, tanto as que constituem as elites, quanto a classe trabalhadora, é a competência para compreender ou não a missão histórica que lhes cabe no sentido do que poderíamos chamar de emancipação do homem de suas carências e misérias. Justamente a propósito da ruptura de Caio Prado Júnior com a sua classe e do seu ingresso no Partido Comunista, dizia ele, em 1991, que essa ruptura conclamava os membros da elite a "que descobrissem que construíam e reproduziam, cotidianamente, a cadeia dentro da qual prenderam e degradaram a sua consciência social, a condição humana e a ausência de saídas históricas dentro de falsos padrões de democracia" (13).

São as biografias gestadas nesses pontos de desencontro que mostram melhor como cada um é alcançado e golpeado por situações sociais (e/ou étnicas) duplamente orientadas, ambíguas ou indefinidas; situações em que o próprio indivíduo, singular e "não-normal", tem que decidir os rumos de sua vida e neles os rumos da sociedade. São momentos biograficamente cruciais porque exigem de 
quem é assim alcançado criatividade, iniciativa, desafios e superações. É o indivíduo quem se vê desafiado a encontrar saída para a ambigüidade e a construir a unidade nova de uma situação dilacerada. Toda a obra de Florestan Fernandes, inclusive seus textos propriamente políticos, é marcada por uma certa concepção da responsabilidade social e histórica da pessoa, do sujeito, uma visão que lhe dá um lugar muito peculiar e criativo em face das formulações clássicas da sociologia.

As situações que propõem a ruptura, que definem um quadro de fragilidade dos mecanismos de reprodução de relações sociais e políticas, mas também de "estados de consciência", tanto se apresentam na vida do rico quanto na do pobre. Tanto atravessam a biografia e a história familiar de Caio Prado Júnior, descendente de ilustre linhagem de grandes capitalistas e senhores de terras e escravos, desde o século XVIII, quanto atravessam a biografia do ex-escravo João de Camargo, que toma para si, para ter um nome e se tornar gente, o sobrenome de seu senhor. E tanto se apresentam na biografia do intelectual quanto na do operário - tanto atravessam a biografia de Antonio Candido, o operário da palavra, quanto a de Luiz Inácio Lula da Silva, o operário da ferramenta. Esses dois protagonistas das nossas lutas sociais contemporâneas são descobertos juntos pelo sociólogo porque neles se dá o reencontro do pensar e do fazer; porque há neles uma comunidade de destino que a História havia cindido.

Para Florestan Fernandes, esses são momentos de redefinição da consciência e de ressocialização das pessoas. Há uma espécie de processo educativo permanente nas relações sociais em crise. Foi esse, certamente, o fator que levou o professor Florestan Fernandes a se interessar pela educação e pelo estudo sociológico dos processos educativos, como já o fizera outro ilustre mestre da Universidade de São Paulo, o professor Fernando de Azevedo, de quem ele foi assistente. A sociologia aplicada, um dos campos em que se tornou autoridade reconhecida, não só poderia desenvolver técnicas sociais de mudança social provocada, mas também interessar-se pelas relações entre biografia e mudança social, de modo que os alvos mais generosos da mudança induzida tivessem na ressocialização dos agentes, através da escola, um meio de afirmação (14). Esse, aliás, era o espírito que norteara a fundação da Universidade de São Paulo e que tem tido em Fernando de Azevedo, em Antonio Candido eem Florestan Fernandes alguns de seus apóstolos mais notáveis.

As situações ambivalentes e limites reaparecem em seus diferentes estudos sob a forma de ruptura com o conformismo e com o destino. Se por um lado as biografias que documentam o repetitivo são por ele consideradas fundamentais para a compreensão do funcionamento da sociedade, por outro são igualmente fundamentais as biografias transgressivas e as personalidades divergentes. O que interessa ao sociólogo, enquanto sociólogo, é o que o homem faz de seu destino nessas horas cruciais. Uma boa parte da sociologia de Florestan Fernandes é dedicada ao entendimento das dificuldades sociais para compreensão dessas alternativas e seu mau ou insuficiente aproveitamento; ao entendimento da perdição dos que não tiveram força, discernimento, coragem e determinação para tomar a História nas mãos, naquela fração de tempo histórico em que os dilemas permanecem diante dos olhos e da consciência de cada um. Durkheim faz da anomia, do desencontro entre as transformações no substrato das relações sociais e as representações e normas sociais que deveriam corresponder-lhes, o centro de sua sociologia. Como Marx, faz também do atraso da consciência em relação às relações sociais que ela mediatiza, faz da alienação o núcleo de sua sociologia. Do mesmo modo, Florestan Fernandes toma o desencontro do homem com sua obra como, no fundo mesmo, o seu objeto central de estudo. Essencialmente, o sociólogo aparece aí dominado pela indagação das razões do desencontro, suas conseqüências, os problemas que advirão para o próprio homem.

O professor Florestan foi e é, enfim, o sociólogo do reencontro do homem consigo mesmo, o enigma e desafio que deu origem à sociologia. Esse homem não só tem uma vida na História, mas tem também a responsabilidade da contrapartida dessa imersão no $\mathrm{Ou}$ tro: ele tem uma história de Vida.
14 Cf. Florestan Fernandes, Ensaios de Sociologia Geral e Aplicada, op. cit., esp. pp. 160-219. 